Western University

Scholarship@Western

Biology Publications

Biology Department

4-13-2010

\title{
Production of Organic Acids and Adsorption of Cd on Roots of Durum Wheat (Triticum turgidum L. var. durum)
}

Bolaji A. Adeniji

Mackenzie T. Budimir-Hussey

Sheila M. Macfie

smacfie@uwo.ca

Follow this and additional works at: https://ir.lib.uwo.ca/biologypub

Part of the Biology Commons

Citation of this paper:

Adeniji, Bolaji A.; Budimir-Hussey, Mackenzie T.; and Macfie, Sheila M., "Production of Organic Acids and Adsorption of Cd on Roots of Durum Wheat (Triticum turgidum L. var. durum)" (2010). Biology Publications. 39.

https://ir.lib.uwo.ca/biologypub/39 
Production of organic acids and adsorption of Cd on roots of durum wheat (Triticum turgidum L. var durum)

Bolaji A. Adeniji, Mackenzie T. Budimir-Hussey and Sheila M. Macfie* Department of Biology, University of Western Ontario, Canada

* corresponding author

Department of Biology, University of Western Ontario, 1151 Richmond St. N., London, ON, Canada N6A 5B7

e-mail: smacfie@uwo.ca

phone: 519-661-2111 ext. 86487

fax: 519-661-3935 


\begin{abstract}
A number of isolines of durum wheat (Triticum turgidum var durum) differ in their translocation of $\mathrm{Cd}$. In the field, the high isolines accumulate twice the $\mathrm{Cd}$ in leaves and grain when compared to the low isolines. The hypothesis that differential accumulation of Cd is associated with differential production of organic acids was tested by measuring Cd content in tissues, Cd partitioning within the root, and organic acids in tissues. In solution culture, the high and low isolines of W9261-BG did not differ in any of the variables measured. Within W9260-BC, the low isoline had half the Cd in its shoot, 30\% more tightly-bound $\mathrm{Cd}$ in the root and higher concentrations of fumaric, malic, and succinic acids in the root compared to the high isoline. Differential Cd accumulation may be linked to differential adsorption and retention of $\mathrm{Cd}$ in the roots of the low $\mathrm{Cd}$ accumulating isolines, possibly via chelation with organic acids.
\end{abstract}

Keywords: Cadmium; LMWOAs; Triticum turgidum; Isolines; Adsorption. 


\section{Introduction}

Durum wheat (Triticum turgidum L. var durum) is one of the main staple foods consumed worldwide, and is one of several crops that tend to accumulate high concentrations of cadmium (Cd) when grown in Cd-contaminated soil (Hart et al. 2006). Health concerns associated with Cd-contaminated crops have caused the international food standard organization, the Codex Alimentarius Commission, to propose a $0.2 \mathrm{mg}$ Cd $\mathrm{kg}^{-1}$ limit for wheat and rice grains meant for the international market (CAC 2005). This proposed limit, when adopted, may have dire consequences for major durum wheat exporters, such as Canada, where the natural accumulation of $\mathrm{Cd}$ in the grains varies from

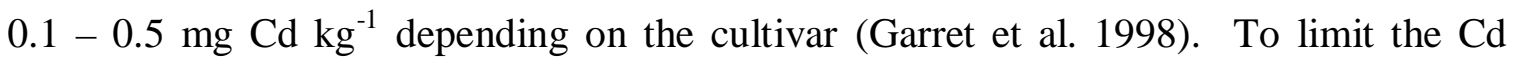
concentration in wheat grains, five pairs of isolines of durum wheat were derived through classical breeding (Clarke et al. 1997a). Each pair of isolines can be categorized as high and low Cd-accumulating isolines, with the high member of each pair having twice the Cd content in their leaves and seeds when compared to the low Cd-accumulating isoline (Clarke et al. 1997a; Harris and Taylor 2001).

Many factors including rates of Cd uptake, xylem translocation from root to shoot and production of metal-binding chelators have been studied to date but the observed differential partitioning of $\mathrm{Cd}$ in these isolines has yet to be clearly explained. Berkelaar and Hale (2000) associated the differences in Cd accumulation between durum wheat cultivars Kyle (high Cd in grain) and Arcola (low Cd in grain) with differences in their root morphology; roots of Arcola accumulated 30\% more Cd and also had more root tips and greater root surface area. Further, Hart et al. (1998) observed that Cd binds to the 
root cell wall in durum wheat and the concentration dependence of the binding was linear, suggesting that apoplastic binding might be responsible for the observed decrease in root to shoot $\mathrm{Cd}$ translocation in the low Cd-accumulating cultivars. However, the relative involvement of the apoplast in differential $\mathrm{Cd}$ accumulation in the isolines of durum wheat remains unverified. Harris and Taylor (2001) determined that the movement of $\mathrm{Cd}^{2+}$ into the grains of durum wheat treated with ${ }^{109} \mathrm{Cd}^{2+}$ was partly correlated with remobilization of Cd from the flag leaf.

The roles of chelators such as phytochelatins (PCs) and low molecular weight organic acids (LMWOAs) in differential Cd accumulation in durum wheat have also been studied. Stolt et al. (2003) determined that neither PC chain length nor PC isoform varied with differential $\mathrm{Cd}$ accumulation in spring bread wheat (Triticum aestivum L.) and durum wheat. They hypothesized that differential accumulation of $\mathrm{Cd}$ in wheat grain might be due to differential Cd partitioning in the root. Thus, a closer look at the mechanisms of adsorption, absorption and storage of Cd within roots might aid in elucidating the mechanism behind differential Cd concentrations in the isolines of durum wheat. Cieśliński et al. (1998) investigated the effects of LMWOAs exuded in the rhizosphere of durum wheat cultivars Arcola (low Cd in grain) and Kyle (high Cd in grain). They found that Kyle exuded more LMWOAs into the rhizosphere when compared to Arcola, and suggested that this might be responsible for increased mobilization and uptake of Cd in Kyle. It is imperative to know the relative contribution of endogenous organic acids in either conferring metal-tolerance to plants or in facilitating uptake of metals by roots as we seek characteristics that define low Cdaccumulating cultivars. 
The objective of the current study was to investigate the relationship between LMWOAs and Cd in the shoot and root tissues to test the hypothesis that differential accumulation of Cd is associated with differential production of LMWOAs. In addition, we also investigated the partitioning of $\mathrm{Cd}$ in roots by measuring the relative amounts of Cd adsorbed to the roots (an estimate of the apoplast) and in the roots (an estimate of the symplast). The experimental results were modeled using visual MINTEQ 2.53 (Gustafsson 2006), a chemical speciation program, to better understand the proportion of Cd that could be bound to various LMWOAs produced in the plant tissues.

\section{Materials and Methods}

Plant material, Germination and Growth Conditions

Two pairs of isolines of durum wheat (Triticum turgidum L. var durum) originally derived by Clarke et al. (1997a) were used. The two pairs are designated as W9260-BCL and W9260-BC-H, and W9261-BG-L and W9261-BG-H (L= low Cd-accumulating isoline, $\mathrm{H}=$ high $\mathrm{Cd}$-accumulating isoline). The pairs were selected from $\mathrm{F}_{4: 6}$ families that segregated for Cd concentration in the grain; the W9260-BC pair was derived from the cross DT617/DT471 and the W9261-BG pair from the cross DT630/DT471 (Clarke et al. 1997a). DT617 and DT630 are high Cd-accumulating and DT471 is low Cdaccumulating (Clarke et al. 2002). The isoline pairs and parental lines were developed under field conditions in Saskatchewan Canada and North Dakota USA (reviewed in Grant et al. 2008). Phenotypic analysis of the $F_{2}$ generations of five different crosses of durum wheat indicated that $\mathrm{Cd}$ accumulation in the grain was controlled by a single gene, 
dominant for low Cd-accumulation (Clarke et al. 1997b). Recently, Knox et al. (2009) used quantitative trait locus (QTL) analysis of double haploid $\mathrm{F}_{1}$ plants derived from low and high Cd-accumulating parental lines of durum wheat to map the locus of the gene for Cd-accumulation (Cdu1) on chromosome 5B.

The concentrations of $\mathrm{Cd}$ in the leaves of the isolines are highly correlated $(\mathrm{r}>0.87$, $\mathrm{p}<0.01$ ) with the concentrations of Cd in the grain (Clarke et al. (1997b); therefore, the phenotype (differential Cd-accumulation) can be assessed without having to wait for the grain to fill. The W9260-BC and W9261-BG isoline pairs were selected based on a preliminary study in which differential Cd accumulation (i.e. high Cd-accumulating isoline contained twice the $\mathrm{Cd}$ in the leaves compared to the low $\mathrm{Cd}$-accumulating isoline) was reproduced in hydroponic culture (Bahrami, McGarvey and Macfie, unpublished data). Seedlings were grown following a modified method based on Archambault et al. (2001). Briefly, seeds were surface-sterilized with 1\% sodium hypochlorite for $20 \mathrm{~min}$, rinsed three times with distilled water, and thereafter imbibed overnight in aerated solution containing $0.005 \mathrm{~g} \mathrm{~L}^{-1}$ Vitavax (a systemic fungicide; Uniroyal Chemical Ltd, Calgary, AB, Canada). Aquaria were each filled with $10 \mathrm{~L}$ of nutrient solution containing $1.0 \mathrm{mM} \mathrm{Ca}\left(\mathrm{NO}_{3}\right)_{2}, 1.0 \mathrm{mM} \mathrm{K}_{2} \mathrm{HPO}_{4}, 0.4 \mathrm{mM} \mathrm{KNO} 3,0.3 \mathrm{mM}$ $\mathrm{NH}_{4} \mathrm{NO}_{3}, 0.1 \mathrm{mM} \mathrm{K}_{2} \mathrm{SO}_{4}, 0.01 \mathrm{mM} \mathrm{FeCl}, 0.01 \mathrm{mM} \mathrm{Na} \mathrm{EDTA}_{3}, 6.0 \mu \mathrm{M} \mathrm{H}_{3} \mathrm{BO}_{3}, 2.0 \mu \mathrm{M}$ $\mathrm{MnCl}_{2}, 0.5 \mu \mathrm{M} \mathrm{ZnSO}_{4}, 0.15 \mu \mathrm{M} \mathrm{CuSO}_{4}$, and $0.1 \mu \mathrm{M} \mathrm{Na}_{2} \mathrm{MoO}_{4}$, adjusted to $\mathrm{pH}$ 6, and the treated seeds were placed on mesh suspended over the aerated nutrient solution. The aquaria were completely covered for $24 \mathrm{~h}$ with black plastic to prevent seeds from drying out. Thereafter, the aquaria were uncovered and placed in a controlled environment room 
set to a day/night temperature regime of $20 / 18^{\circ} \mathrm{C}$ with a $16 \mathrm{~h}$ light period and a $8 \mathrm{~h}$ dark period; the fluorescent light intensity was $200 \pm 15 \mu \mathrm{mol} \mathrm{m} \mathrm{m}^{-2} \cdot \mathrm{s}^{-2}$. Seedlings of uniform size were selected for hydroponic culture experiments.

Experimental Treatment

On day 6, the seedlings were transferred into 1.4 L culture vessels (four plants per vessel and four replicate vessels per treatment unless stated otherwise) filled with the nutrient solution described above ( $\mathrm{pH}$ 6), and aerated. Seedlings were placed between thin pieces of upholstery foam and suspended in slits cut into the lids of the culture vessels. The culture vessels were covered with black cloth to limit algal growth, and placed in the controlled environment room. The nutrient solutions were replenished every other day to safeguard against nutrient deficiencies. The solutions in culture vessels were brought up to $1.4 \mathrm{~L}$ daily with $\mathrm{dH}_{2} \mathrm{O}$ to account for water loss due to evapotranspiration. Eight-dayold plants were treated with $\mathrm{CdCl}_{2} \cdot 4 \mathrm{H}_{2} \mathrm{O}(0$ and $0.1 \mu \mathrm{M})$ added to fresh nutrient solutions. This low concentration of Cd was chosen to mimic the Canadian prairie soil

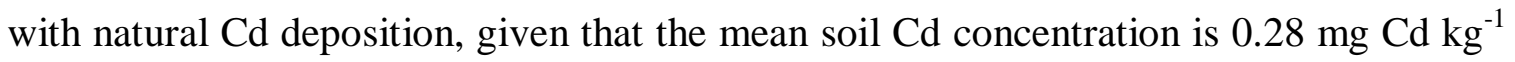
(Chan and Hale 2004) and Cd concentrations greater than $0.1 \mu \mathrm{M}$ have been shown to induce stress in durum wheat (Archambault et al. 2001). The aerated nutrient solutions with or without $\mathrm{Cd}^{2+}$ supplementation were replenished every other day. Plant tissues were harvested on day 8 after treatment with or without $\mathrm{CdCl}_{2}$, and fresh weight was recorded. 


\section{Measurement of Cd}

To estimate the amount of $\mathrm{Cd}$ adsorbed to the root surface, half of the roots in each culture vessel $(n=3)$ were rinsed in $\mathrm{dH}_{2} \mathrm{O}$ for $30 \mathrm{~s}$ followed by a 30 min wash in $1 \mathrm{mM}$ $\mathrm{CaSO}_{4}$ and another $30 \mathrm{~s}$ wash in $\mathrm{dH}_{2} \mathrm{O}$ (Gadapati and Macfie 2005); Cd adsorbed to the root surface will be removed by cation exchange between $\mathrm{Cd}^{2+}$ and $\mathrm{Ca}^{2+}$. To measure the total amount of Cd associated with the roots, the other half of the roots in each vessel were washed in $\mathrm{dH}_{2} \mathrm{O}$ for $30 \mathrm{~s}$ to rinse the nutrient solution from the root surface. With these treatments, the amount of adsorbed Cd can be obtained by subtracting the amount of $\mathrm{Cd}$ in the $\mathrm{CaSO}_{4}$-washed roots from the amount of $\mathrm{Cd}$ in the unwashed roots. All plant tissues were blotted dry with Kimwipe ${ }^{\circledR}$ tissues, separated into roots and shoots, ovendried at $60^{\circ} \mathrm{C}$ to constant weight and analyzed for $\mathrm{Cd}$.

Dried plant tissues were cut into $2-3 \mathrm{~mm}$ pieces and approximately $0.1-0.2 \mathrm{~g}$ were weighed into individual test tubes. To the individual samples, $1.5 \mathrm{~mL}$ nitric acid (Omni-Trace $\left.{ }^{\circledR}\right)$ was added. Each test tube was capped with a marble to keep the sample in the tube and allow for pressure release. Racks of test tubes were allowed to sit at room temperature overnight, then placed on a sand-filled tray and heated to $90-100^{\circ} \mathrm{C}$ until the tissues were fully digested. Tomato leaves (NIST standard reference material \#1573a) and reagent blanks were included in the digestion process to allow for easy determination of percentage recovery of $\mathrm{Cd}$ in the tissue sample and possible contamination. When cooled to room temperature, the samples were filtered using $9 \mathrm{~cm}$ VWR brand filter paper (qualitative 413) and the volume brought up to $25 \mathrm{~mL}$ with 
$\mathrm{dH}_{2} \mathrm{O}$. The samples were analyzed for total Cd by inductively coupled plasma- atomic emission spectroscopy (ICP-AES) using a Perkin-Elmer Optima 3300 dual view ICPAES, with a RF generator power of 1300 Watts, gas flow rate of $15 \mathrm{~L} \mathrm{~min}^{-1}$, auxiliary flow rate of $0.5 \mathrm{~L} \mathrm{~min}{ }^{-1}$, nebulizer flow rate of $0.8 \mathrm{~L} \mathrm{~min}^{-1}$, pump (for sample) flow rate of $1.0 \mathrm{~L} \mathrm{~min}^{-1}$, and an analyte line of $\mathrm{Cd} 226.507 \mathrm{~nm}$, with a detection limit of $8-10 \mathrm{ppb}$ for Cd.

\section{Organic Acid Analyses}

Plant tissues were carefully monitored during growth and development to ensure adequate nutrient supply and to raise the confidence in organic acid data because LMWOAs may be produced by nutrient-deficient plants as in the case of lupin, Lupinus albus L. cultivars Minori and Nelly, where exudation of citric acid increased significantly under phosphorus deficiency (Egle et al. 2003).

Organic acids in the plant tissues

Following harvest, plant tissues (roots and shoots) were prepared using the modified method of Sanita di Toppi et al. (2007). The roots were severed from the shoot and fresh tissues (approximately $1.0 \mathrm{~g}$ ) were ground to powder in a chilled mortar using liquid nitrogen, collected in $50 \mathrm{~mL}$ centrifuge tubes and frozen $\left(-80^{\circ} \mathrm{C}\right)$ until analysis. For analysis, $5 \mathrm{~mL}$ of $\mathrm{dH}_{2} \mathrm{O}$ was added to the tissue samples and the mixture was heated for 20 min in a water bath at $80^{\circ} \mathrm{C}$ to denature the degradative enzymes. The mixture was 
then centrifuged at $2500 \mathrm{x}$ g for $10 \mathrm{~min}$ at $25^{\circ} \mathrm{C}$ and $300 \mu \mathrm{L}$ of the supernatant was injected directly on a Dionex Ion Chromatograph (IC) for the determination of LMWOAs (see next section). Where appropriate, the supernatant was diluted with $\mathrm{dH}_{2} \mathrm{O}$ to reduce overloaded peaks and obtain more resolved and identifiable peaks.

Identification of organic acids

The method used for the separation and identification of LMWOAs using IC followed that of Liu et al. (2007) with slight modifications. Briefly, the LMWOAs were separated with a Dionex ICE-ASI Ion exclusion column (4 x $250 \mathrm{~mm})$ with the following column conditions: $1.5 \mathrm{mM}$ heptafluorobutyric acid (HFBA) as eluent, eluent flow of 80 on the dial, nitrogen pressure of 7.5 psi, run time was $11.90 \mathrm{~min}$, and $40 \mu \mathrm{L}$ injection volume. The suppressor settings for the Dionex ion chromatograph were as follows: regenerant was 9.7 mM tetrabutyl ammonium hydroxide (TBAOH), regenerant flow was $3.5 \mathrm{ml} \mathrm{min}^{-}$ ${ }^{1}$ and nitrogen pressure was 15 psi. Spiking experiments involving the addition of known concentrations of organic acid standards to the supernatants were carried out in order to validate the identities of the observed peaks.

Data Analyses

All statistical analyses were performed using SigmaStat Version 2.03. Two-way analysis of variance (ANOVA) was used to determine the effects due to isolines and Cd treatment on biomass and Cd content and Tukey's test was used to determine significant 
differences between means ( $\mathrm{P}<0.05)$. The t-test was used to determine the differences in proportion of Cd adsorbed to roots of low and high Cd-accumulating isolines. Twoway ANOVA was used to determine the differences in mean values of total LMWOAs in low and high Cd-accumulating isolines. Due to significant interactions between isolines and individual LMWOAs, one-way ANOVAs were used to analyze the isolines, and Tukey’s test was used to determine significant differences between treatments.

Visual MINTEQ (version 2.53), a chemical speciation program, was used to estimate the proportion of measured Cd that was bound to each of the measured LMWOAs in the tissues. Fumaric acid did not exist in the visual MINTEQ database, so we approximated Cd-fumaric acid interactions by replacing fumaric acid with tartaric acid, the most similar LMWOA in the database (fumaric acid pka1=3.02, pka2=4.44; tartaric acid pka1=2.98, pka2=4.34). The average amounts of LMWOAs and Cd in the Cd-treated roots and shoots of each low and high Cd-accumulating isoline were modeled; these amounts were calculated by multiplying mean concentration by mean mass for each tissue. Modelling was done at $\mathrm{pH}$ values $4.5-7.5$ to span the range of $\mathrm{pH}$ in the cytoplasm, vacuole and cell wall. In a review by Kurkdjian and Guern (1989) the pH of the cytoplasm ranged from 6.8 to 7.5 in roots and was 7.5 in leaves, and the $\mathrm{pH}$ of the vacuole ranged from 4.6 to 6.0 in roots and was 5.3 in leaves. Cell wall free space $\mathrm{pH}$ ranges from 4.5 to 6.5 (Jacobs and Ray 1976). We recognize that other metal-binding sites (such as the cell wall matrix) exist within plant tissue, the model simply gives an estimate of the potential for Cd to bind to the various LMWOAs. 


\section{Results}

Plant Biomass and Cd Distribution

During the course of the experiments, all plants appeared healthy and there were no visible signs of Cd-induced stress or nutrient deficiencies. Neither the fresh nor dry weights of W9260-BC shoots varied between treatments (Fig. 1a and 1b, respectively). The fresh and dry weights of W9260-BC roots were more variable, with the root fresh weight of the low Cd-accumulating isoline being higher in treated plants (Fig 1a) and the dry weight for the high Cd-accumulating isoline being lower in control plants (Fig. 1b). Based on the ratio of dry weight to fresh weight, shoots of W9260-BC contained 85 95\% water, and roots contained 91 - 96\% water. The root and shoot fresh (Fig 1d) and dry (Fig 1e) weights of W9261-BG did not differ between treatments or isoline. Based on the ratio of dry weight to fresh weight, W9261-BG shoots contained 95 - 96\% water, and roots contained 97 - $98 \%$ water.

The Cd concentration in the shoots of the high Cd-accumulating isoline of W9260-BC was two-fold greater than that of the low Cd-accumulating isoline when treated with $0.1 \mu \mathrm{M} \mathrm{Cd}$ (Fig. 1c). No differences were found in concentrations of Cd in Cd-treated roots of the low and high Cd-accumulating isolines of W9260-BC. In W9261BG (Fig. 1f), the Cd concentrations in the root and shoot tissues did not vary with treatment or isoline. However, Cd concentrations in Cd-treated W9261-BG were 50 75\% lower in shoots than those of Cd-treated W9260-BC, and at least 90\% lower in roots. 
The proportions of Cd that were adsorbed to Cd-treated roots of the two pairs of isolines were investigated to further decipher the mechanisms behind the differential Cd accumulation in the aboveground tissues. In the low Cd-accumulating isoline of W9260BC, only $8.2 \pm 5.1 \%$ of the $\mathrm{Cd}$ was adsorbed to the root, which was significantly lower $(\mathrm{P}=0.01)$ than the proportion of $\mathrm{Cd}$ adsorbed to the root of the high $\mathrm{Cd}$-accumulating isoline (43.9+5.7\%). In W9261-BG, the percentage of Cd adsorbed to the root did not differ $(\mathrm{P}=0.88)$ between isolines; low $=31.8+3.0 \%$; high $=33.8+12.0 \%$.

\section{Organic Acid Content in Durum Wheat Tissues}

In the low Cd-accumulating isoline of W9260-BC, total LMWOA concentrations were higher in roots and shoots treated with Cd relative to their controls (Fig. 2a). In contrast, total LMWOAs in the high Cd-accumulating isoline treated with Cd declined in the root and did not vary in the shoots compared to their respective controls (Fig. 2a).

Each of citric, fumaric, malic, oxalic and succinic acids were found in both isolines of W9260-BC (Fig. 2b-f). Concentrations of oxalic acid (Fig. 2e) were $4-20$ times higher in shoots and $5-10$ times higher in roots as compared to the other LMWOAs. In the low Cd-accumulating isoline, concentrations of fumaric, malic, oxalic and succinic acids in the root, and of fumaric and succinic acids in the shoot were greater in the Cd-treated plants. Contrasting results were found in the high Cd-accumulating isoline where concentrations of citric acid in the root and shoot, and of succinic acid in the root, decreased in Cd-treated plants. 
No differences in total LMWOA concentration were found in roots and shoots of low and high Cd-accumulating isolines of W9261-BG treated with Cd relative to their controls; although, shoots of the high Cd-accumulating isoline had higher concentrations of LMWOAs than the low Cd-accumulating isoline regardless of Cd-exposure (Fig. 3a).

In W9261-BG, only four LMWOAs were found in the root and shoot tissues, and these were in the order oxalic $>$ malic $>$ fumaric $=$ succinic (Fig. 3 b-e). With only two exceptions, treatment with Cd did not affect the concentrations of any LMWOA in roots or shoots within any pair of isolines. The two exceptions were for the low Cdaccumulating isoline grown in the presence of $\mathrm{Cd}$; the concentrations of oxalic acid in the root (Fig. 3d) and succinic acid in the shoot (Fig. 3e) were higher than their respective controls.

Modeling using visual MINTEQ

Our experimental results were modeled to estimate the proportion of total Cd that was bound to the various LMWOAs. Estimated speciation of Cd at different pHs in the root and shoot tissues of the low and high Cd-accumulating isolines of W9260-BC and W9261-BG is presented in Table 1. In no instance was the formation of Cd-fumaric or Cd-succinic acid complexes predicted to account for more than $0.15 \%$ of the total Cd in any tissue (data not shown) so these two LMWOAs were not included in the table. Within the range of $\mathrm{pH}$ tested (4.5 - 7.5), greater than $88 \%$ of the total Cd in both tissues of all isolines was predicted to be bound to oxalic acid, the LMWOA in highest abundance. Up to $1.5 \%$ of the total Cd was predicted to be the $\mathrm{Cd}^{2+}$ free ion even though 
the concentrations of LMWOAs were $1-3$ orders of magnitude higher than the concentrations of $\mathrm{Cd}$ in the tissues. Although only approximately $2-10 \%$ of the total $\mathrm{Cd}$ in the tissue was predicted to be bound to citric or malic acids, some interesting patterns appeared.

In W9260-BC, in which the high Cd-accumulating isoline accumulated two-fold higher concentrations of $\mathrm{Cd}$ than did the low Cd-accumulating isoline, the speciation of Cd did not differ markedly in the shoot tissues (Table 1). However, the proportion of Cd estimated to be bound to citric acid was approximately 8 times higher in the roots of the high Cd-accumulating isoline than in the low Cd-accumulating isoline, across the range of $\mathrm{pH}$ modeled. In the roots of the high Cd-accumulating isoline, the proportion of $\mathrm{Cd}$ estimated to be bound to malic acid was about one third of that in the low isoline.

In W9261-BG, in which no differential translocation of Cd was detected, the distribution of $\mathrm{Cd}$ in the roots of the isolines did not differ but the proportion of $\mathrm{Cd}$ estimated to be bound to malic acid in the shoots was 10-fold higher in the high Cdaccumulating isoline (Table 1).

\section{Discussion}

During the course of the experiments, both pairs of isolines showed no symptoms of Cdinduced stress; hence, we are confident that the results reflect constitutive physiological differences between the isolines.

Under our experimental conditions, only one pair of isolines (W9260-BC) showed the expected two-fold higher concentrations of Cd in shoots of the high Cd-accumulating 
isoline. Elevated concentrations of $\mathrm{Cd}$ in the shoots of the high Cd-accumulating isoline were not associated with decreased concentrations in the roots; however, the large variance in measurements for the low Cd-accumulating isoline in our study may have reduced the chances of finding a significant difference. Harris and Taylor (2004) and Hart et al. (2006) also found no differences in the root Cd uptake between the durum wheat isoline pairs of 8982-TL and W9262-339A.

The lack of differential Cd accumulation in the shoots of the W9261-BG isolines in our study may be attributable to the relatively low $\mathrm{Cd}$ content in their tissues. The reason for Cd-treated W9261-BG isolines accumulating 50 - 90\% less Cd and having $50 \%$ dry mass as compared the W9260-BC isolines is not clear. However, it is unlikely to be related to a genetic difference between W9260-BC and W9261-BG. While the two pairs of isolines share the same low Cd-accumulating parent (DT471) and have different high Cd-accumulating parents (DT617 and DT630; Clarke et al. 1997a), the Cdaccumulating trait is specific to differential Cd-accumulation; the isoline pairs do not differ in differential translocation of $\mathrm{Ca}, \mathrm{Cu}, \mathrm{Fe}, \mathrm{K}, \mathrm{Mn}$, Na or Zn, nor in agronomic traits including yield (Clarke et al. 2002). It is possible that hydroponic culture or conditions in the controlled environment room resulted in reduced transpiration of the W9261-BG isolines, which could explain reduced growth and Cd-uptake. However, in a preliminary study performed 1 year prior to this study, differential accumulation of Cd was observed in the W9261-BG pair of isolines.

Concentrations of Cd were $4-10$ times higher in roots than in shoots, which is a common result that has been attributed to apoplastic binding of $\mathrm{Cd}$ to the root cell walls. For example, Perriguey et al. (2008) found that maize had 28 times greater concentrations 
of $\mathrm{Cd}$ in roots than in shoots, and suggested that binding of $\mathrm{Cd}$ in the root apoplast reduced Cd translocation to the shoot. Hart et al. (1998) and Chan and Hale (2004) also speculated that most of the root-Cd in durum wheat cultivars is restricted to the apoplast, and Cd was mostly associated with the cell wall in roots of $N$. tabacum and $T$. caerulescens (Boominathan et al. 2003). In our study $<40 \%$ of the Cd was adsorbed to the root. However, the method we used to desorb Cd from the root may not have removed $100 \%$ of the apoplastic Cd, especially past the first few layers of the root cortex.

Nevertheless, desorption of $\mathrm{Cd}$ in our study revealed that differential Cd accumulation in the W9260-BC isolines of durum wheat was associated with more Cd being sequestered in the putative root symplast of the low Cd-accumulating isoline. This is consistent with Harris and Taylor (2004) who reported that reduced Cd translocation in shoots of a low Cd-accumulating isoline of durum wheat was associated with a lower Cd concentration in the xylem sap; they hypothesized that the roots of the low Cdaccumulating isolines have an efficient mechanism of retaining $\mathrm{Cd}$. It is possible that this retention may be attributable to sequestration and/or complexation with organic ligands in the root symplast, possibly LMWOAs in the vacuole.

In our study, roots of the isoline in which a greater proportion of $\mathrm{Cd}$ was retained in the root did contain greater concentrations of LMWOAs. Within the low Cdaccumulating isoline of W9260-BC, treatment with Cd resulted in increased concentrations of fumaric, malic, oxalic and succinic acids in the roots. In contrast, concentrations of malic, citric, fumaric and succinic acids decreased in the roots in response to $\mathrm{Cd}$ in the high $\mathrm{Cd}$-accumulating isoline. Because the concentrations of oxalic acid were high relative to other LMWOAs in both high and low Cd-accumulating 
isolines, chelation with oxalic is unlikely to explain differential retention of $\mathrm{Cd}$ in the roots. Even though the modeling results confirm that over $88 \%$ of the $\mathrm{Cd}$ in the root tissues was predicted to be complexed with oxalic acid, differences in concentrations of other LMWOAs might explain differential retention of the remaining Cd, especially when one combines absolute concentrations of Cd and LMWOAs with the results of the chemical speciation modelling. Specifically, the 2.5-fold higher estimated proportions of Cd-malic acid in roots of the low Cd-accumulating isoline relative to the high Cdaccumulating isoline suggests that some of the $\mathrm{Cd}$ retained in the root might be complexed with malic acid. Interestingly, the root of the high Cd-accumulating isoline had 8-fold higher estimated proportion of Cd-citric acid compared to the low Cdaccumulating isoline. Although not tested here, it is possible that $\mathrm{Cd}$ is translocated to the shoot as a citric acid complex. In the shoot, Cd-malic acid was the second-most prevalent Cd-complex in both low and high Cd-accumulating isolines.

The lack of differences in concentrations of LMWOAs in roots and shoots of W9261-BG grown in control solution as compared to those from plants treated with Cd may be related to the fact that these isolines did not differ in Cd content, and very little Cd was taken up by these isolines. However, the estimated higher proportion of Cd bound to malic acid in the shoot of the high Cd-accumulating isoline is consistent with the results of the W9260-BC isolines and suggests that Cd-malic complexes might be important to Cd sequestration.

Our results indicate that Cd-organic acid complexes sequestered in the root might explain the restricted $\mathrm{Cd}$ translocation from root to shoot in the low Cd-accumulating isolines of durum wheat. Also, though not tested in this study, there is a possibility that 
the increased LMWOAs measured in the shoot of the low Cd-accumulating isoline might form complexes with $\mathrm{Cd}$ and thus restrict $\mathrm{Cd}$ loading into the grains. Similar results have been reported by Guo et al. (2007) who found an increased production of LMWOAs in maize (Zea mays L.) roots treated with Cd, suggesting that LMWOAs produced might be involved in Cd tolerance and detoxification. Similar to the studies on isolines of durum wheat, LMWOAs have been implicated in Zn hyperaccumulation and tolerance in Arabidopsis halleri by Zhao et al. (2000), who found no significant differences in concentrations of citric and malic acids in shoots but a positive increase in concentrations of both acids in roots treated with Zn. In contrast, Nakamura et al. (2008) detected citric and malic acids in the xylem exudate of oilseed rape (Brasicca napus L.), providing inconclusive evidence for citric acid and malic acid as Cd chelators in the xylem exudate.

The yet to be identified gene responsible for differential Cd-accumulation in durum wheat appears to code for a trait that affects retention of $\mathrm{Cd}$ in the root (Berkelaar and Hale 2000) and/or root to shoot translocation of Cd (Chan and Hale 2004, Harris and Taylor 2004) as opposed to uptake of Cd into the root. While we know the trait for low Cd-accumulation in the grain is dominant (Clarke et al. 1997b), and the gene is located on chromosome 5B (Knox et al. 2009), the function of this gene is not known. The results of our study indicate that the answer may lie in organic acid biochemistry. It is tempting to speculate that the gene for differential Cd accumulation affects a pathway that results in inter-conversion of citric and malic acids. The more malic acid produced the more $\mathrm{Cd}$ is bound in the root, the more citric acid produced the more $\mathrm{Cd}$ is translocated to the shoot. It is equally plausible that the gene directly affects sequestration of Cd in the root; for example, there might be a Cd-specific transporter that 
moves Cd into the vacuole where it is subsequently chelated with malic acid or another LMWOA. As soon as the gene is identified, experiments can begin to elucidate its function.

\section{Conclusions}

Differential Cd accumulation in shoots of isolines of durum wheat may be linked to the differential Cd partitioning and retention in the root symplast of the low Cd-accumulating isolines. The increased retention of $\mathrm{Cd}$ in the root of low Cd-accumulating isolines may be associated with LMWOA-Cd complexes. The role of individual LMWOAs in forming complexes with $\mathrm{Cd}$ in the roots of the low Cd-accumulating isoline is worthy of further investigation as this might enhance our understanding of the roles of naturally-produced chelators as they relate to food safety.

\section{Acknowledgements}

The authors gratefully acknowledge the Natural Sciences and Engineering Research Council Discovery Grant Program for financial support. We also thank Dr. John M. Clarke for providing seeds, Dr. Charles Wu for ICP-AES analyses, and Dr. George Lazarovits and Mr. Igor Lalin for assistance with ion chromatography. 


\section{References}

Archambault DJ, Marentes E, Buckley W, Clarke J, Taylor GJ (2001) A rapid, seedling based bioassay for identifying low cadmium-accumulating individuals of durum wheat (Triticum turgidum L.). Euphytica 117:175-182

Berkelaar E, Hale B (2000) The relationship between root morphology and cadmium accumulation in seedlings of two durum wheat cultivars. Can J Bot 78: $381-387$

Boominathan R, Doran PM (2003) Organic acid complexation, heavy metal distribution and the effect of ATPase inhibition in hairy roots of hyperaccumulator plant species. J Biotechnol 101: 131-146

CAC (Codex Alimentarius Commission) (2005) Joint FAO/WHO Food Standards Programme. Twenty-Eight Session, Rome, Italy 4-9 July 2005. Report of the $37^{\text {th }}$ session of the Codex Committee on Food Additives and Contaminants, 25-29 April 2005. Para. 175, Appendix XXVI. The Hague, the Netherlands. Available via http://www.codexalimentarius.net/web/archives.jsp?year=05. Accessed 10 Aug,2009

Chan DY, Hale BA (2004) Differential accumulation of Cd in durum wheat cultivars: uptake and retranslocation as sources of variation. J Exp Bot 55:2571-2579

Cieśliński G, Van Rees KCJ, Szmigielska AM, Huang PM (1997) Low molecular-weight organic acids released from roots of durum wheat and flax into sterile nutrient solutions. J Plant Nutr 20:753-764 
Clarke JM, Leisle D, DePauw RM, Thiessen LL (1997a) Registration of five pairs of durum wheat genetic stocks near-isogenic for cadmium concentration. Crop Sci $37: 297$

Clarke JM, Leisle D, Kopytko GL (1997b) Inheritance of cadmium concentration in five durum wheat crosses. Crop Sci 37:1722-1726

Clarke JM, Norvell WA, Clarke FR, Buckley WT (2002) Concentration of cadmium and other elements in the grain of near-isogenic durum lines. Can J Plant Sci 82:27-33

Egle K, Römer W, Keller H (2003) Exudation of low molecular weight organic acids by Lupinus albus L., Lupinus angustifolius L. and Lupinus luteus L. as affected by phosphorus supply. Agronomie 23:511-518

Gadapati WR, Macfie SM (2006) Phytochelatins are only partially correlated with Cd-stress in two species of Brassica. Plant Sci 170: 471-480

Garrett RG, MacLaurin AL, Gawalko R, Tkachuk R, Hall, GEM (1998) A prediction model for estimating the cadmium content of durum wheat for soil chemistry. J Geochem Explor 64:101-110

Grant CA, Clarke JM, Duguid S, Chaney RL (2008) Selection of breeding of plant cultivars to minimize cadmium accumulation Sci Total Environ 390:301-310

Guo B, Peng Z, Han F, Shan X, Lin J (2007) Study of low molecular weight organic acids in maize roots under the stress of cadmium using capillary zone electrophoresis. J Sep Sci 30:2742-2747

Gustafsson JP (2006) Visual MINTEQ version 2.53. Available via http://www.lwr.kth.se/English/OurSoftware/vminteq/index.htm. Accessed 10 Aug 2009 
Harris NS, Taylor GJ (2001) Remobilization of cadmium in maturing shoots of near isogenic lines of durum wheat that differ in grain cadmium accumulation. J Exp Bot 52:1473-1481

Harris NS, Taylor GJ (2004) Cadmium uptake and translocation in seedlings of near isogenic lines of durum wheat that differ in grain cadmium accumulation. BMC Plant Biol 4:4-15

Hart JJ, Welch RM, Norvell WA, Kochian LV (2006) Characterization of cadmium uptake, translocation and storage in near-isogenic lines of durum wheat that differ in grain cadmium accumulation. New Phytol 172:261-271

Hart JJ, Welch RM, Norvell WA, Sullivan LA, Kochian LV (1998) Characterization of cadmium binding, uptake, and translocation in intact seedlings of bread and durum wheat cultivars. Plant Physiol 116:1413-1420

Jacobs M, Ray PM (1976) Rapid auxin-induced decrease in free space pH and its relationship to auxin-induced growth in maize. Plant Physiol 58:203-209

Knox RE, Pozniak CJ, Clarke FR, Clarke JM, Houshmand S, Singh AK (2009) Chromosomal location of the cadmium uptake gene (Cdu1) in durum wheat. Genome 52:741-747

Kurkdjian A, Guern J (1989) Intracellular pH: measurement and importance in cell activity. Annu Rev Plant Physiol Plant Mol Biol 40:271-303

Liu J, Qian M, Cai G (2007) Variations between rice cultivars in root secretion of organic acids and the relationship with plant cadmium uptake. Environ Geochem Health 29:189-195

Nakamura S, Akiyama C, Sasaki T, Hattori H, Chino M (2008) Effect of cadmium on the 
chemical composition of xylem exudate from oilseed rape plants (Brassica napus L.). Soil Sci Plant Nutr 54:118-127

Perriguey J, Sterckema T, Morel J (2008) Effect of rhizosphere and plant-related factors on the cadmium uptake by maize (Zea mays L.). Environ Exp Bot 63:333-341

Sanita di Toppi L, Vurro E, Rossi L, Marabottini R, Musetti R, Careri M, Maffini M, Mucchino C, Corradini C, Badiani M (2007) Different compensatory mechanisms in two metal-accumulating aquatic macrophytes exposed to acute cadmium stress in outdoor artificial lakes. Chemosphere 68:769-780

Stolt JP, Sneller FEC, Bryngelsson T, Lundborg T, Schat H (2003) Phytochelatin and cadmium accumulation in wheat. Environ Exp Bot 49:21-28

Zhao FJ, Lombi E, Breedon T, McGrath SP (2000) Zinc hyperaccumulation and cellular distribution in Arabidopsis halleri. Plant Cell Environ 23:507-514 
Table 1 Estimated percentage of total Cd apportioned to Cd-organic complexes or the free $\mathrm{Cd}^{2+}$ ion in shoots and roots of durum

wheat grown for 8 days in nutrient solution supplemented with $0.1 \mu \mathrm{M} \mathrm{CdCl}_{2}$. Total Cd in each tissue was calculated as concentration of Cd x tissue dry weight.

\begin{tabular}{|c|c|c|c|c|c|c|c|c|c|c|c|c|c|c|c|c|}
\hline & $\mathrm{pH}$ & 4.5 & 5 & 5.5 & 6 & 6.5 & 7 & 7.5 & & 4.5 & 5 & 5.5 & 6 & 6.5 & 7 & 7.5 \\
\hline $\begin{array}{l}\text { W9260-BC } \\
\text { Shoot }\end{array}$ & Low & \multicolumn{7}{|c|}{ Total Cd = $2.1 \mu \mathrm{g}$} & High & \multicolumn{7}{|c|}{ Total Cd $=3.7 \mu \mathrm{g}$} \\
\hline & Cd-citric & 0.03 & 0.1 & 0.2 & 0.3 & 0.4 & 0.4 & 0.4 & & 0.1 & 0.3 & 0.6 & 1.1 & 1.5 & 1.7 & 1.7 \\
\hline & Cd-malic & 3.6 & 5.3 & 6.5 & 7 & 7.2 & 7.3 & 7.3 & & 4.6 & 6.6 & 8.0 & 8.7 & 8.9 & 8.9 & 8.9 \\
\hline & Cd-oxalic & 95.1 & 93.5 & 92.2 & 91.5 & 91.2 & 91.1 & 91.1 & & 94.4 & 92.3 & 90.5 & 89.4 & 88.9 & 88.6 & 88.5 \\
\hline & $\mathrm{Cd}^{2+}$ & 0.9 & 0.8 & 0.8 & 0.7 & 0.7 & 0.7 & 0.7 & & 0.9 & 0.8 & 0.7 & 0.7 & 0.7 & 0.7 & 0.7 \\
\hline Root & Low & \multicolumn{7}{|c|}{ Total Cd $=11.0 \mu \mathrm{g}$} & High & \multicolumn{7}{|c|}{ Total Cd $=7.1 \mu \mathrm{g}$} \\
\hline & Cd-citric & 0.04 & 0.1 & 0.2 & 0.5 & 0.7 & 0.8 & 0.8 & & 0.3 & 0.8 & 2.1 & 4.0 & 5.8 & 6.8 & 7.2 \\
\hline & Cd-malic & 1.0 & 1.5 & 1.9 & 2.1 & 2.2 & 2.2 & 2.2 & & 0.4 & 0.6 & 0.8 & 0.8 & 0.8 & 0.8 & 0.8 \\
\hline & Cd-oxalic & 97.5 & 97 & 96.5 & 96.1 & 95.8 & 95.7 & 95.6 & & 97.7 & 97.2 & 95.9 & 93.9 & 92.2 & 91.2 & 90.8 \\
\hline & $\mathrm{Cd}^{2+}$ & 1.3 & 1.1 & 1.1 & 1.1 & 1.0 & 1.0 & 1.0 & & 1.5 & 1.3 & 1.2 & 1.2 & 1.1 & 1.1 & 1.1 \\
\hline \multirow{6}{*}{$\begin{array}{l}\text { W9261-BG } \\
\text { Shoot }\end{array}$} & & & & & & & & & & \multirow{2}{*}{\multicolumn{7}{|c|}{ Total Cd $=0.3 \mu \mathrm{g}$}} \\
\hline & Low & \multicolumn{7}{|c|}{ Total Cd $=0.5 \mu \mathrm{g}$} & High & & & & & & & \\
\hline & Cd-citric & 0.05 & 0.1 & 0.3 & 0.6 & 0.9 & 1.0 & 1.1 & & 0.03 & 0.1 & 0.2 & 0.3 & 0.4 & 0.4 & 0.5 \\
\hline & Cd-malic & 0.4 & 0.6 & 0.7 & 0.8 & 0.8 & 0.8 & 0.8 & & 4.0 & 5.8 & 7.1 & 7.6 & 7.8 & 7.9 & 7.9 \\
\hline & Cd-oxalic & 98.2 & 98.1 & 97.8 & 97.5 & 97.2 & 97.0 & 96.9 & & 95.0 & 93.2 & 91.9 & 91.1 & 90.8 & 90.7 & 90.7 \\
\hline & $\mathrm{Cd}^{2+}$ & 1.3 & 1.1 & 1.1 & 1.1 & 1.0 & 1.0 & 1.0 & & 0.9 & 0.8 & 0.8 & 0.8 & 0.8 & 0.8 & 0.7 \\
\hline Root & Low & \multicolumn{7}{|c|}{ Total Cd $=0.6 \mu \mathrm{g}$} & High & \multicolumn{7}{|c|}{ Total Cd $=0.4 \mu \mathrm{g}$} \\
\hline & Cd-citric & 0.05 & 0.1 & 0.3 & 0.6 & 0.9 & 1.0 & 1.1 & & 0.03 & 0.1 & 0.2 & 0.4 & 0.6 & 0.7 & 0.7 \\
\hline & Cd-malic & 0.6 & 1.0 & 1.2 & 1.3 & 1.4 & 1.4 & 1.4 & & 0.5 & 0.7 & 0.9 & 1.0 & 1.1 & 1.1 & 1.6 \\
\hline & Cd-oxalic & 97.9 & 97.7 & 97.3 & 96.9 & 96.6 & 96.4 & 96.4 & & 98.2 & 98.0 & 97.8 & 97.5 & 97.3 & 97.2 & 97.1 \\
\hline & $\mathrm{Cd}^{2+}$ & 1.3 & 1.1 & 1.1 & 1.1 & 1.0 & 1.0 & 1.0 & & 1.3 & 1.1 & 1.0 & 1.0 & 1.0 & 1.0 & 1.0 \\
\hline
\end{tabular}




\section{Figure Legends}

Fig. 1 Effect of Cd on root and shoot fresh weights (a,d), dry weights (b,e) and Cd uptake $(c, f)$ of low and high Cd-accumulating isolines of durum wheat. Different lower case letters denote significant differences $(\mathrm{P}<0.05)$ within each tissue type. Error bars represent standard error of the mean (SEM) of three replicates

Fig. 2 Concentrations of low molecular weight organic acids in root and shoot tissues of W9260-BC; a total, b citric, c fumaric, d malic, e oxalic, f succinic. Different lower case letters within each tissue denote significant difference $(\mathrm{P}<0.05)$ between treatments. Error bars represent SEM of four replicates

Fig. 3 Concentrations of low molecular weight organic acids in root and shoot tissues of W9261-BG; a total b fumaric, c malic, d oxalic, e succinic. Different lower case letters within each tissue denote significant difference $(\mathrm{P}<0.05)$ between treatments. Error bars represent SEM of four replicates 
Fig. 1
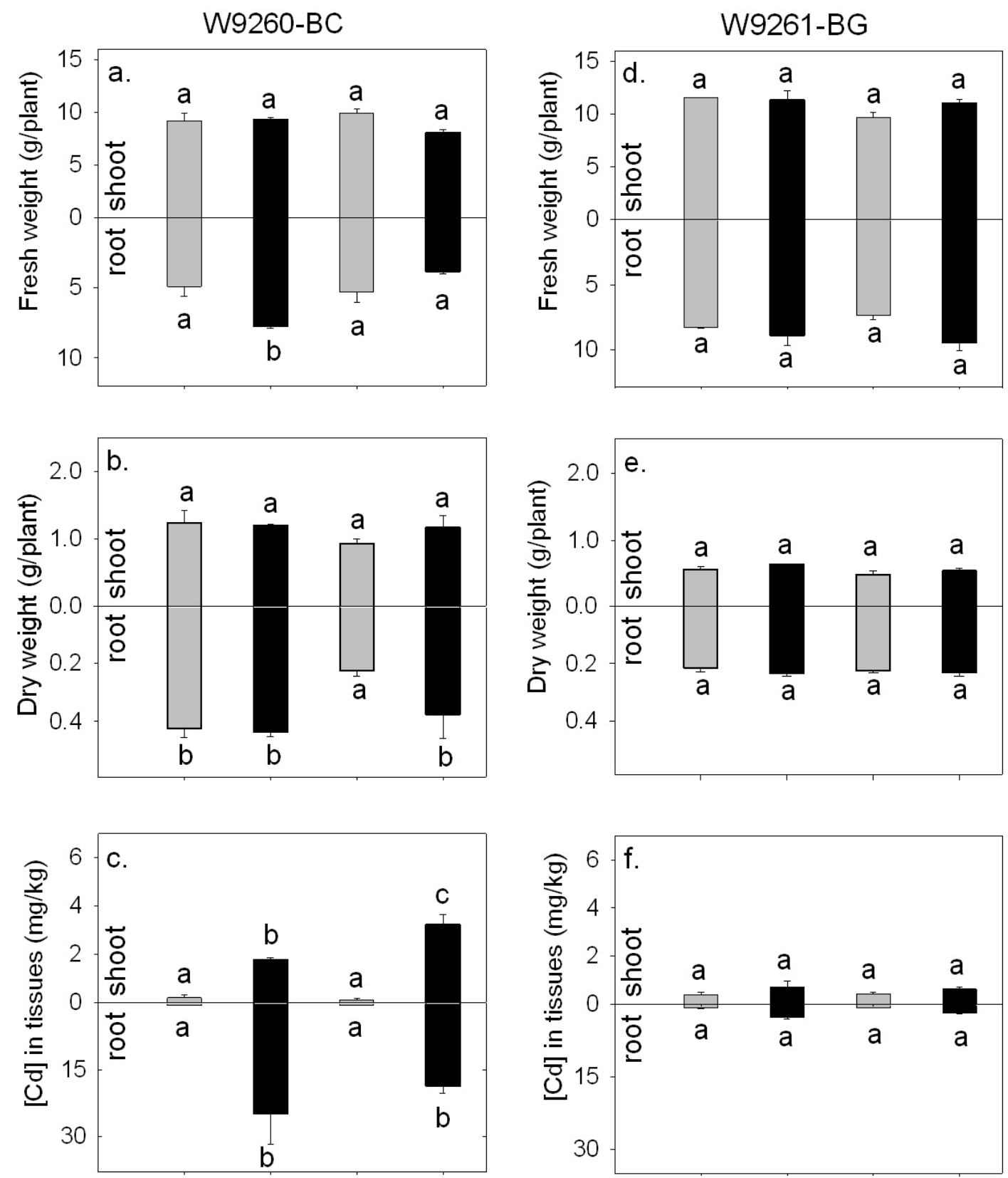

Control Treated Control Treated Low Isoline

High Isoline

Control Treated Control Treated Low Isoline

High Isoline 
Fig. 2

W9260-BC
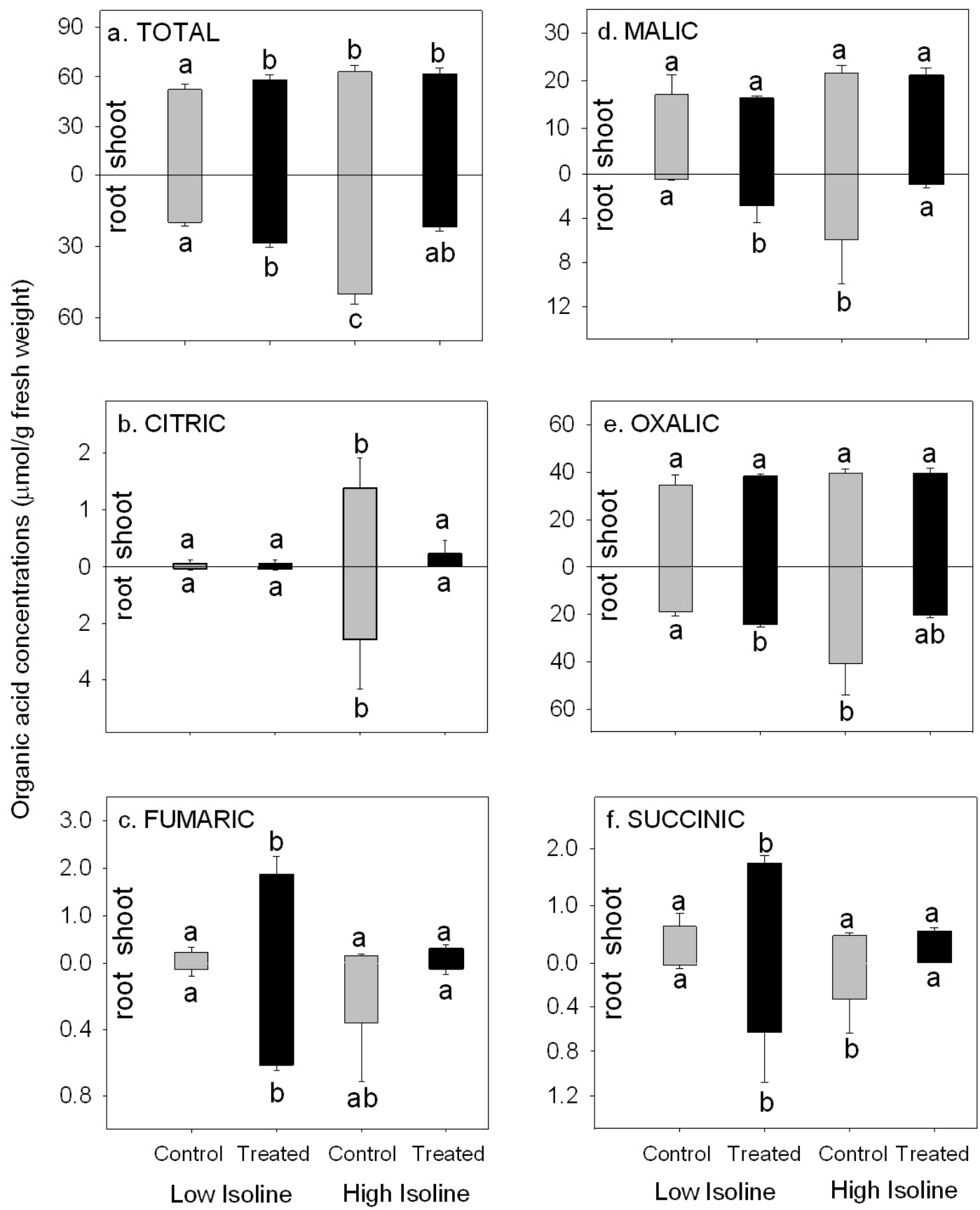
Fig. 3

W9261-BG

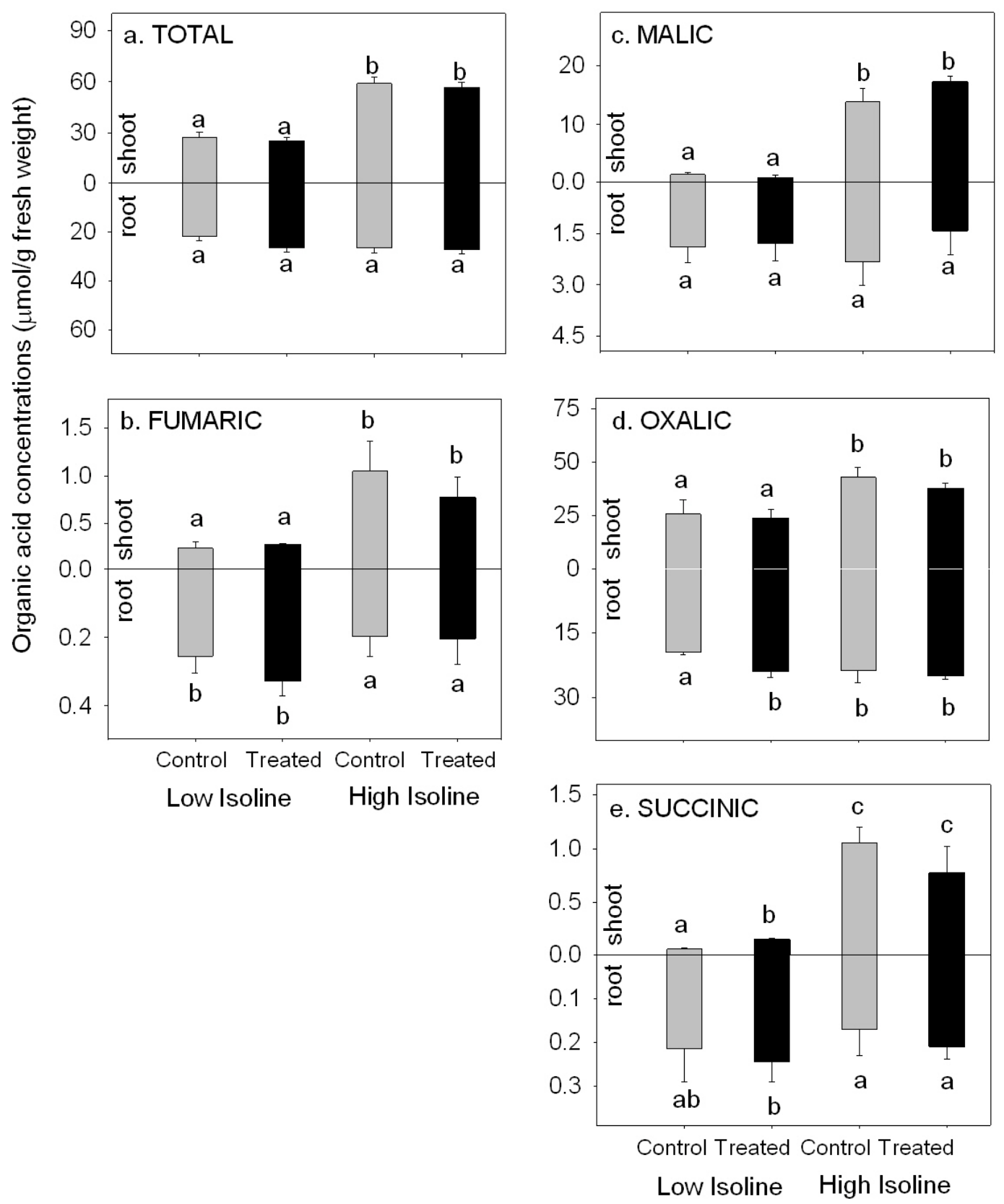

